\title{
TURISMO RURAL E AGRICULTURA FAMILIAR DE BASE AGROECOLÓGICA: UMA EXPERIÊNCIA NO MUNICÍPIO DE ABREU E LIMA - PE
}

\author{
Filipe Augusto Xavier Lima ${ }^{1}$, Gustavo Silva Carreiro de Souza², Jorge Luiz Schirmer Mattos ${ }^{3}$ \\ ${ }^{1}$ Doutorando do Programa de Pós-Graduação em Extensão Rural da Universidade Federal de Santa Maria (UFSM), \\ filipeaxlima@yahoo.com.br \\ 2 Engenheiro Agrônomo e Licenciado em Ciências Agrícolas, gsilvacs@hotmail.com \\ ${ }^{3}$ Professor do Departamento de Educação da Universidade Federal Rural de Pernambuco (UFRPE), \\ js-mattos@uol.com.br
}

http://dx.doi.org/10.5902/223613087230

\section{RESUMO}

Pretende-se, no presente trabalho, analisar a relação entre turismo rural e agricultura familiar e seus impactos sobre o desenvolvimento local, a partir um estudo de caso realizado no Espaço Agroecológico Sítio São João, em Abreu e Lima, Estado de Pernambuco. Foi identificada neste estudo a manifestação de atividades ligadas ao desenvolvimento do agroecoturismo e, com isso, buscou-se identificar aspectos do processo de transição agroecológica mediante observação direta das práticas sociais existentes na propriedade. Nas visitas ao local ficou evidente o potencial para o aproveitamento de uma modalidade turística que une o lazer e a preservação/conservação ecológica dos agroecossistemas, sendo um valor agregado que favorece a relação da família com os visitantes, interessados em pesquisar ou simplesmente conhecer e consumir alguns produtos beneficiados no local. A metodologia utilizada foi a observação direta do fenômeno e, em um segundo momento, foi realizada uma pesquisa bibliográfica sobre as principais temáticas aqui discutidas.

Palavras-chave: agroecologia, agroecoturismo, transição agroecológica.

\section{ABSTRACT \\ RURAL TOURISM AND FAMILY FARM BASE AGROECOLOGICAL: AN EXPERIENCE IN THE CITY OF ABREU E LIMA - PE}

It is intended, in the present work was to analyze the relationship between family farming and rural tourism and its impacts on local development, from a case study conducted at St. John Ranch Area Agroecological in Abreu e Lima, State of Pernambuco. Identified in this study was the demonstration of activities related to the development of agro-ecotourism and, therefore, sought to identify aspects of the transition process agroecological through direct observation of social practices on the property. In site visits was evident the potential for exploitation of a type of tourism that combines recreation and preservation/conservation of ecological agroecosystems, being an aggregate value which favors family relationship with visitors interested in researching or just meet and eat some processed products on site. The methodology used was direct observation of the phenomenon and, in a second step, we performed a literature search on the key themes discussed here.

Key Words: agroecology, agro-ecotourism, agro-ecological transition. 


\section{INTRODUÇÃO}

No intuito de analisar a relação entre turismo rural e agricultura familiar e seus impactos sobre o desenvolvimento local, elegeu-se, como objeto de análise, a experiência do Espaço Agroecológico Sítio São João, junto aos agricultores familiares do município de Abreu e Lima Pernambuco, numa perspectiva de aproveitamento para o agroecoturismo, modalidade que se nutre do tratamento sustentável dos recursos existentes no meio rural incentivando práticas de visitação que apresentam como finalidades a educação e a sensibilização quanto aos métodos de manejo característicos dos sistemas agroecológicos.

Diante desse cenário, é importante frisar que a Agroecologia é considerada uma nova abordagem científica da agricultura e apresenta como finalidade integrar diversos aspectos agronômicos, ecológicos e socioambientais sobre as técnicas utilizadas e seus impactos na sociedade como um todo (CAPORAL; COSTABEBER; PAULUS, 2006).

O local da pesquisa foi sugerido pelo Curso de Licenciatura em Ciências Agrícolas e o Programa de Pós-Graduação em Extensão Rural e Desenvolvimento Local (Posmex), da Universidade Federal Rural de Pernambuco (UFRPE), por possuir significativa diversidade em termos de aproveitamento agroecológico, como também por já existir uma parceria entre a universidade e a família que administra o espaço. Assim, foram realizadas, no mês de maio de 2010, quatro visitas à propriedade, localizada no município de Abreu e Lima, e uma visita à Feira Agroecológica das Graças, bairro nobre da capital pernambucana. É nesta feira que os agricultores familiares de base agroecológica comercializam os produtos beneficiados no Sítio São João.

A partir dessas visitas foram identificados alguns indicadores que podem ser analisados em uma proposta de desenvolvimento do agroecoturismo no local, tais como: a presença constante de visitantes no sítio, interessados em conhecer, pesquisar e desfrutar do ambiente natural que ali predomina; na área correspondente à agrofloresta são realizadas trilhas ecológicas utilizadas para a sensibilização ambiental, bem como para o entretenimento dos visitantes, mesmo que estes tenham um propósito educacional; os principais aspectos da cultura e dos costumes tradicionais da família mantêm-se vivos, o que representa um fator de extrema atratividade para o turista que busca o meio rural; a prática rotineira da visitação e os programas de qualificação oferecidos pelo Centro de Desenvolvimento Agroecológico SABIÁ deram à família desenvoltura e uma didática interessante quanto ao tratamento com os visitantes. A alimentação complementa o roteiro na intenção de aproximar os visitantes das práticas de beneficiamento dos produtos agroecológicos cultivados no local, bem como a importância do consumo de alimentos que atendem aos padrões de produção e consumo agroecológicos.

Os indicadores acima representam, portanto, a maior justificativa de realização deste trabalho, uma vez que foi possível identificar nessas manifestações a presença das dimensões histórica, social, educativa e cultural que fazem parte de todo o processo de transição agroecológica. Neste momento, o artigo busca também abordar brevemente o cruzamento entre agroecologia e agroecoturismo numa perspectiva de complementaridade. Isso significa que, dentro de um sistema agroecológico, qualquer atividade que seja a ele agregada deve agir como um vetor de desenvolvimento, sendo uma ferramenta que fortalece a atividade principal.

Tendo como pilares a cidadania e a democracia, a transição agroecológica busca o fortalecimento da agricultura familiar, pressupondo o uso de metodologias de intervenção participativa, capazes de incluir os agricultores na tomada de decisões, valorizando os saberes científico e popular. Por outro lado, estimula parcerias e formas associativas em todos os níveis, além de respeitar as diferenças de gênero, de culturas e de grupos de interesses. Estabelece metas 
compatíveis com as condições socioeconômicas, com os interesses e as necessidades das populações que fazem parte da construção de uma agricultura sustentável.

A dimensão social da transição agroecológica contempla, ainda, um processo de ação coletiva de caráter identitário, através do qual os agricultores estabelecem relações de interesse comum no sentido de buscar o reconhecimento, a inclusão social e a elaboração de alternativas para resolver seus próprios problemas. Eles têm oportunidade de expressar seus pontos de vista, desejos, crenças e expectativas para seu futuro como agricultores e cidadãos. O resultado é a satisfação e a realização pessoal, derivadas da participação cidadã na discussão, planejamento e experimentação de sistemas de produção agroecológica. Nesse sentido, a transição agroecológica pretende modificar as relações sociais, que se expressam em uma visão diferenciada do espaço produtivo, da relação com o meio ambiente e entre as pessoas.

Ainda sob a ótica social, pode-se dizer que sendo a produção agroecológica diversificada, o agricultor sempre dispõe de algum produto para o consumo da família. O sistema também proporciona a ocupação de força de trabalho, diferente da agricultura convencional que tem forte sazonalidade e, ainda, tem produção mais distribuída durante o ano. Isto racionaliza o trabalho da família, além de valorizar a participação da mulher e dos jovens nas atividades de beneficiamento responsável pela agregação de mais valor aos produtos. Os avanços, a partir da produção, resultam em grande capacidade de empoderamento e de significativo resgate da auto-estima das famílias agricultoras envolvidas.

Quando observado desde a dimensão social, o processo de transição agroecológica pode ser explicado a partir de uma maior valorização, por parte dos agricultores, de certos benefícios materiais e não materiais, tais como a melhoria da saúde via produção e consumo de alimentos sem contaminantes químicos, assim como a melhoria das condições de trabalho mediante a redução ou eliminação do uso de produtos agrotóxicos na produção. Além disso, trata-se de um processo que pode oferecer também benefícios sociais mais amplos ao conjunto da sociedade, como a oferta de alimentos e produtos com maior qualidade biológica. (COSTABEBER; MOYANO, 2000). Por último, o objetivo final da agricultura deixa de ser exclusivamente o lucro obtido pela produção de commodities e passa a guiar-se, também, por parâmetros e indicadores ecossociais.

A partir da perspectiva de transição agroecológica, com ênfase nas dimensões histórica, social, educativa e cultural abordadas anteriormente, é possível identificar no Sítio São João algumas características inerentes à prática do agroecoturismo, que constitui uma modalidade específica e bem delimitada.

\section{METODOLOGIA}

Quanto aos procedimentos metodológicos, a pesquisa possui caráter empírico, pois grande parte foi desenvolvida no campo, a partir do processo de observação direta, que trata da convivência real do pesquisador com o cotidiano das famílias, (SILVA; MENEZES, 2000). Por outro lado, considera-se que essa observação foi artificial, pois apesar da integração ao referido grupo com o intuito de realizar a investigação, não se fez uso de um roteiro previamente estruturado, o que possibilitou aos pesquisadores uma maior liberdade na observação do cotidiano da comunidade (GIL, 1994). É também uma pesquisa bibliográfica, pois foram consultados textos, artigos e livros relacionados à agroecologia e ao agroecoturismo, no sentido de aproximar mais a teoria do objeto de estudo do presente trabalho. 
A metodologia teve por base uma abordagem qualitativa, através da seleção de um estudo de caso - agricultores familiares no município de Abreu e Lima, Pernambuco. Este município é particularmente ilustrativo por contar com alguns agricultores inseridos em atividades relacionadas ao turismo rural.

A partir de uma ampla revisão bibliográfica, conceitos particularmente importantes na nossa análise como: agricultura familiar, agroecologia, turismo rural e desenvolvimento local estão foram aprofundados.

Em outro momento da investigação utilizou-se os seguintes procedimentos: - visitas aos agricultores familiares para observação direta da rotina dos trabalhos de produção e comercialização; - realização de entrevistas semi-estruturadas com os agricultores, capazes de abranger a totalidade das variáveis objeto de análise na pesquisa (indicadores sociais, técnicos e de produção). Para um diagnóstico da atual situação em que se encontram os produtores do município e a produção de base agroecológica também foram utilizados dados fornecidos por fontes secundárias como o Centro de Desenvolvimento Agroecológico SABIÁ, onde os cadastros de produtores se encontram bastante completos, com informações como localização/endereço das unidades produtivas do município de Abreu e Lima.

\section{RESULTADOS E DISCUSSÃO}

A análise da relação entre turismo rural e agricultura familiar e seus impactos sobre o desenvolvimento local tem como referência a experiência do Espaço Agroecológico Sítio São João, junto aos agricultores familiares do município de Abreu e Lima - Pernambuco.

Levando em consideração as condições atuais das áreas rurais brasileiras, pode-se definir o agroecoturismo como o conjunto de atividades turísticas desenvolvidas no meio rural, comprometido com a sustentabilidade ecológica da produção agropecuária, agregando valor a produtos e serviços, resgatando e promovendo o patrimônio cultural da comunidade (MOLETA; GOIDANICH, 2000).

Esta atividade tem se expandido em alguns países da Europa e no Brasil, visto aliar o convívio do homem urbano junto ao campo, seja mediante uma caminhada ao interior da natureza, um passeio de bicicleta ou pelo relacionamento com uma família de trabalhadores rurais, aliando as atividades de lazer ao desenvolvimento com base agroecológica (MOLETA; GOIDANICH, 2000).

Entende-se que a universalização desse conceito é fundamental, pois pode estimular o estabelecimento de políticas públicas voltadas para a atividade, garantindo a sustentabilidade das práticas agrícolas e das não-agrícolas como forma complementar de obtenção de renda. Nesse sentido, o Sítio São João tem desempenhado um papel importante na exploração do agroecoturismo, que perpassa pelo próprio histórico local.

Localizada na divisa dos municípios de Abreu e Lima e Igarassu, em Pernambuco, a propriedade era cultivada, nas décadas de 60 e 70 do século passado, nos moldes da agricultura convencional. A maioria dos agricultores familiares dessa região, batizada com o nome indígena de Inhamã, se dedicava ao cultivo de mandioca e também mantinha pomares de quintal. Com a plantação exaustiva de mandioca, milho, batata, macaxeira e feijão, tudo produzido com adubos químicos, o solo ficou totalmente improdutivo. 
Em 1988, a comunidade estava envolvida com os trabalhos pastorais da Igreja Católica, que incentivava a prática da apicultura junto aos moradores. Tratava-se de uma parceria entre entidades como o Projeto Tecnológico Alternativo - PTA e o Educater, ligado à Comissão Pastoral da Terra - CPT. O PTA acabou virando o Centro de Desenvolvimento Agroecológico SABIÁ e convidou as comunidades da Região Inhamã para aprenderem a criar abelhas. Formaram assim o Nectarmel, grupo de apicultura que, em pouco tempo, conseguiu um bom número de colméias e uma boa produção.

$\mathrm{Na}$ contramão, a agricultura continuava muito mal. Surgiram questionamentos, pois a produção era muito escassa. Deram, então, início a algumas mudanças implementando técnicas como curva de nível, húmus de composto orgânico, húmus de mandioca, entre outras. Em 1993, já com o trabalho consolidado na apicultura, o grupo decidiu focar mais na agricultura. Fizeram um diagnóstico das propriedades e descobriram que o solo estava totalmente degradado. Apesar dessa constatação, poucas famílias aderiram à idéia de trabalhar com o sistema agroflorestal, em 1994.

Alguns moradores do local, cujo projeto inicial de vida não estava ligado à agricultura, mudaram seus conceitos e, a partir da implantação da agrofloresta, iniciou uma etapa de intercâmbio de conhecimentos, promovendo estágios para técnicos e agricultores de outras comunidades. O Sítio São João passou, então, a ser referência e a receber ONG's, associações de produtores rurais, universidades, escolas técnicas, entre outros visitantes.

Essa trajetória nos permite distinguir algumas variáveis do agroecoturismo, no Sítio São João, tais como: processo histórico da ocupação territorial; estrutura fundiária; características paisagísticas; estrutura agrária local; demais atividades econômicas; características da demanda e tipos de empreendimento (RODRIGUES, 1998). Enquanto atividade não agrícola, o agroecoturismo mostra-se como importante ferramenta no fortalecimento do trabalho realizado no agroecossistema do Sítio São João, sendo uma importante alternativa de geração de renda para as famílias de agricultores.

A expansão das atividades não agrícolas no meio rural constitui-se num movimento socioeconômico importante porque revela uma perspectiva consistente de se mitigar a condição de crescente desemprego da população rural, regida pela contínua modernização da base técnica da produção agrícola, sem a concomitante obsolescência precoce das moradias remanescentes no meio rural brasileiro (LAURENTI; GROSSI, 1999, p. 6-7).

Com a implantação de sistemas agroflorestais, os agricultores do município de Abreu e Lima afirmam que suas famílias passaram a ter uma melhor qualidade de vida, usufruindo ainda de boa alimentação e gerando produtos de qualidade para comercializar. Por outra parte, o Espaço Agroecológico Sítio São João recebe técnicos, estudantes, cientistas e agricultores (Figuras 1 e 2) que, além de visitar e conhecer a sua experiência, também contam com a possibilidade de aprender técnicas agroflorestais, fazer estágios e realizar intercâmbios, o que é gratificante para os proprietários, tendo em vista que um dos seus principais objetivos é difundir ao máximo sua experiência. Corroborando, Zimmermann (2000) coloca que o agroecoturismo deve estar sempre em harmonia com as necessidades e desejos da comunidade local e com o interesse do meio ambiente, fato que contribui para a sustentabilidade da atividade turística, assegurada a partir do tripé composto pelos elementos culturais/antrópicos, ecológicos e econômicos. 


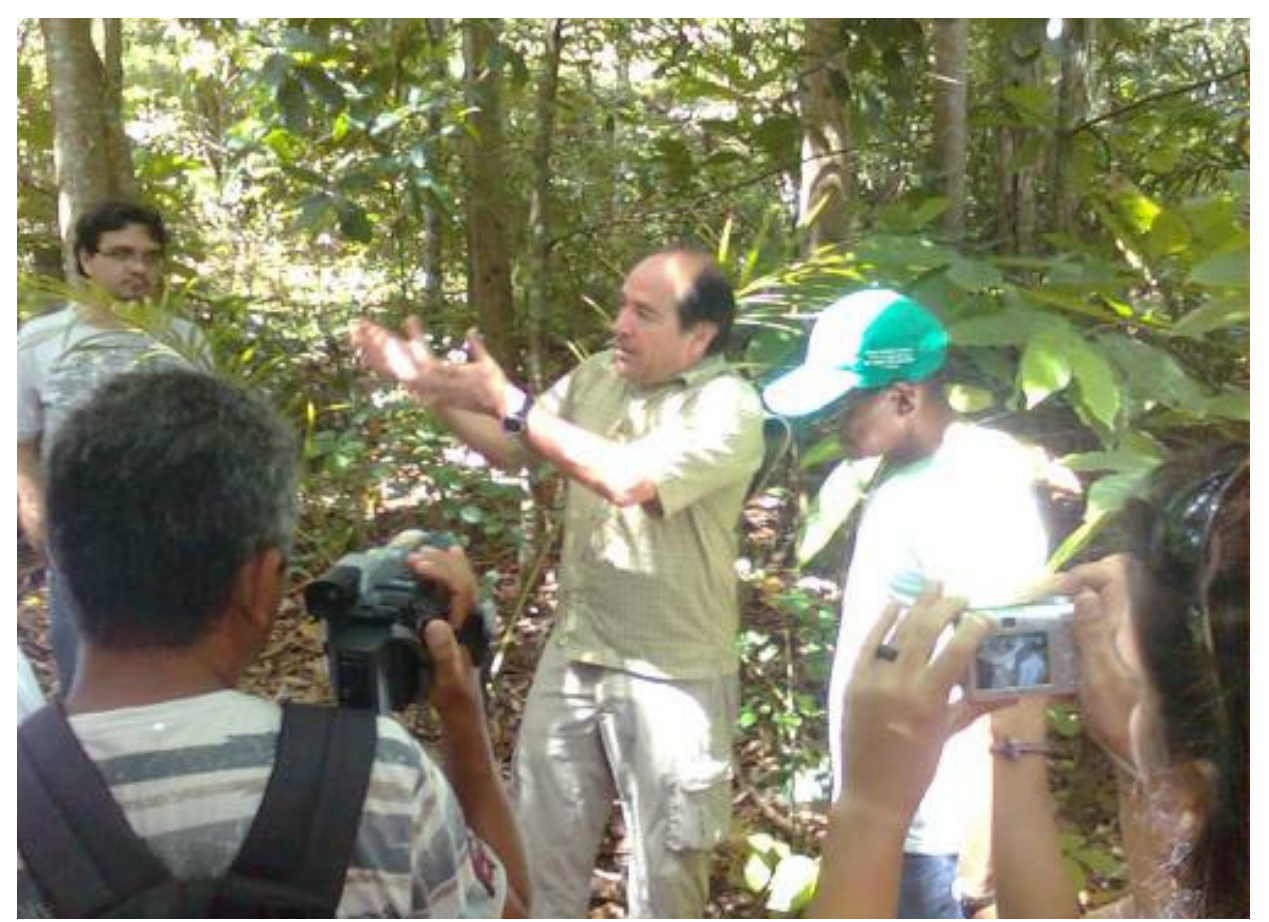

Figura 1. Visita de técnicos, estudantes, cientistas e agricultores ao Sítio São João

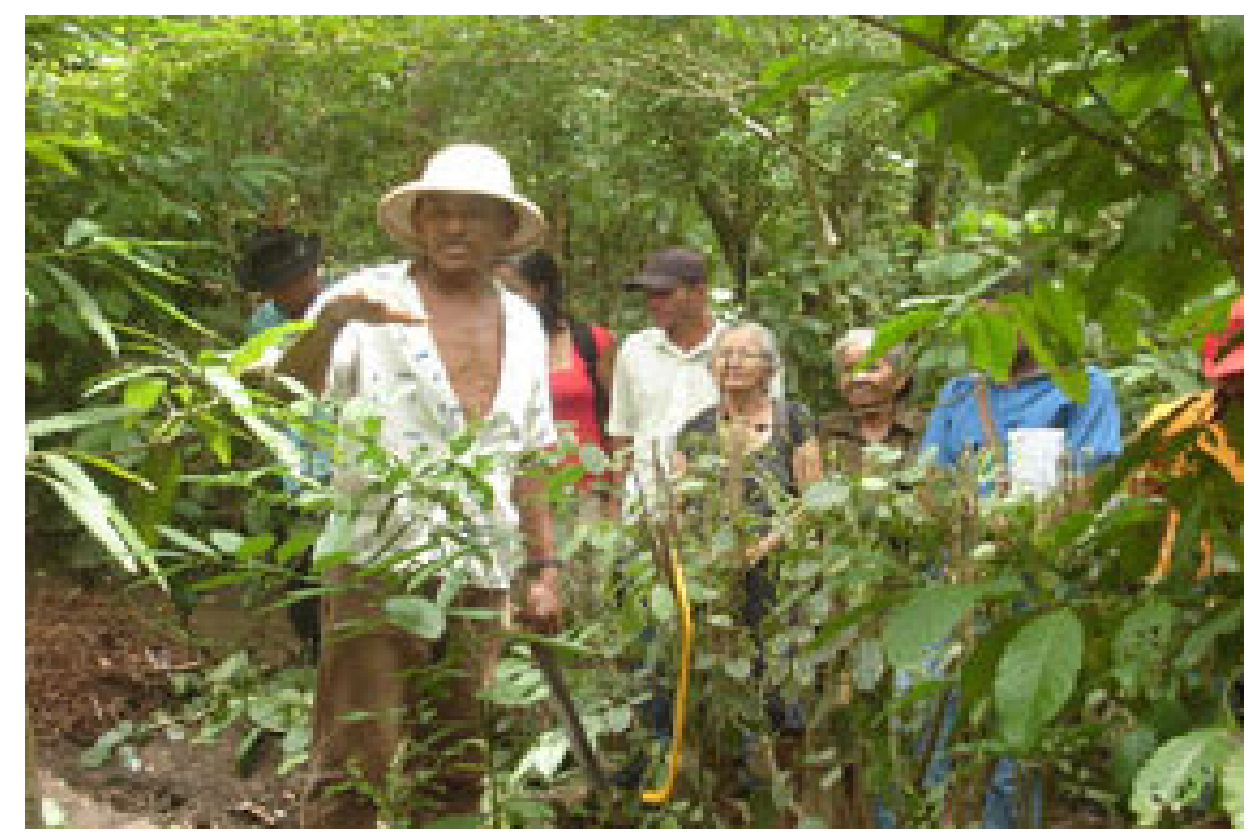

Figura 2. Visita de técnicos, estudantes, cientistas e agricultores ao Sítio São João

\section{CONCLUSÕES}

Este estudo de caso proporcionou uma melhor compreensão de como se dá o funcionamento de um agroecossistema na prática, a partir das visitas que foram realizadas ao Sítio 
São João, em Abreu e Lima-PE. Favoreceu também, a identificação de elementos potenciais no referido espaço agroecológico que podem ser aproveitados em uma proposta de desenvolvimento turístico. A modalidade em questão, o agroecoturismo, surge dos principais fundamentos da agroecologia e, portanto, pode ser utilizado como força complementar ao processo de sustentação do meio rural através da utilização ecologicamente correta de seus recursos.

O Sítio São João, como observado na caracterização feita neste artigo, possui particularidades que a classificam como um espaço, também, de agroecoturismo. A partir dessa discussão, é possível compreender que o maior benefício dessa atividade não agrícola para o local tem sido a melhoria da qualidade de vida das famílias, a partir do incremento da infra-estrutura básica e da adequação das condições de moradia, além da contribuição na formação educacional dos integrantes familiares e da sustentabilidade ecológica de sua propriedade. Isso porque o turismo é uma atividade para a qual os produtores devem capacitar-se, com a finalidade de adquirir novos conhecimentos que elevem o nível dos serviços oferecidos e ampliem o benefício do desenvolvimento local junto ao meio rural. Sendo assim, acredita-se que as práticas de visitação têm favorecido a sensibilização de um número maior de pessoas com relação ao manejo sustentável da agricultura em contraponto com um modelo mais convencional.

\section{REFERÊNCIAS BIBLIOGRÁFICAS}

CAPORAL, F. R; COSTABEBER, J. A; PAULUS, G. Agroecologia: matriz disciplinar ou novo paradigma para o desenvolvimento rural sustentável. Brasília, DF: 2006

COSTABEBER, J. A; MOYANO E. E. Transição Agroecológica e Ação Social Coletiva. 2000.

GIL, A. C. Métodos e Técnicas de Pesquisa Social. São Paulo: Atlas, 1994.

LAURENTI, A. C.; GROSSI, M. E. O novo rural brasileiro: uma análise nacional e regional. Brasília: Embrapa, 1999.

MOLETA, V. F.; GOIDANICH, K. L. Turismo Rural. Porto Alegre, RS: SABRAE/RS, 2000.

RODRIGUES, A. (org.) Turismo e geografia: reflexões teóricas e enfoques regionais. São Paulo: Hucitec, 1998.

SILVA, E. L.; MENEZES, E. M. Metodologia da pesquisa e elaboração de dissertação. Florianópolis: Laboratório de Ensino à Distância da UFSC, 2001.

ZIMMERMANN, A. Planejamento e Organização do Turismo Rural no Brasil. In: ALMEIDA, J. A; FROEHLICH, J. M; RIELD, M (orgs.). Turismo Rural e Desenvolvimento Sustentável. Campinas, SP: Papirus, 2000. 